\title{
Analysis of mechanical-hydraulic bedload deposition control measures
}

\author{
S. Schwindt", M.J. Franca, G. De Cesare, A.J. Schleiss \\ Laboratory of Hydraulic Constructions (LCH), École polytechnique fédérale de Lausanne (EPFL), Station 18, CH-1015 Lausanne, Switzerland
}

\section{A R T I C L E I N F O}

\section{Keywords:}

Bedload

Check dam

Sediment flushing

Sediment trap

Self-emptying

\begin{abstract}
A B S T R A C T
During floods, the bedload transport of steep headwaters can exceed the hydraulic transport capacity of milder downstream reaches where settlements are often situated. Therefore, sediment retention barriers are typically installed upstream of such sensible areas. These barriers trigger bedload trapping via two control mechanisms, either hydraulic or mechanical. Both deposition controls, pertaining to instream sediment trapping structures, are analyzed experimentally in this study. Bedload trapping by hydraulically controlled barriers is prone to sediment flushing, i.e., the remobilization of formerly deposited sediment, in particular when the barrier is simultaneously under- and overflown. In this case, the remobilization rate is close to the bedload transport capacity of the nonconstricted channel. Mechanical deposition control by screens is in turn sensible to the grain size. Thus, both deposition control concepts may fail, and bedload may be transported downstream at a rate corresponding to the transport capacity of headwaters, thereby endangering urban areas. This study shows that the combination of both deposition control concepts is suitable for improving the control of bedload retention. With this combination, undesired sediment flushing of upstream deposits in the channel caused by insufficient hydraulic control is prevented. Furthermore, the uncertainty related to the estimation of the representative grain size in the design of mechanical control barriers is reduced.
\end{abstract}

\section{Introduction}

Heavy rainfalls such as those that occurred in Switzerland in the year 2000 can mobilize large amounts of sediment in the catchment areas of steep mountain rivers (Swiss Federal Office for Water and Geology FOWG, 2002). The high channel gradient in combination with flood discharges can transport considerable amounts of sediment toward downstream reaches, where the grains gradually deposit with decreasing channel slope (D'Agostino and Lenzi, 1999). The transported sediment is essential for the natural ecomorphological pattern of downstream river reaches, but this sediment represents a substantial factor of risks regarding flood protection planning (Gabbud and Lane, 2015; Simoni et al., 2017; Surian and Rinaldi, 2003). In August 2005, the Swiss locality of Bristen witnessed such flood-driven sediment deposits in the village center, causing severe structural damage; and many similar cases have been reported for the same flood event (Bezzola, 2008; Bezzola and Hegg, 2007). These undesired excessive deposits in urban areas can be prevented, e.g., by the installation of instream sediment traps. These structures typically comprise a permeable sediment check dam with openings that limit the downstream bedload transport in the case of floods (Leys, 1976; Piton and Recking, 2016a; Zollinger, 1983).

The typical approach for the design of structural mitigation measures considers check dams, i.e., barriers, with slots or slits for water, and sediment retention. The retention of sediments may be achieved in terms of dosing or sorting. Dosing is the temporary, partial retention of sediment, and sorting is the filtering of coarse material. Sectional and lattice barriers are used to target partial sediment retention in terms of dosing or sorting. Sectional barriers consist of vertical bars; lattice barriers consist of screens with vertical bars and horizontal beams, similar to the application in the present study (cf. Fig. 2 and Hübl et al., 2005, 2003).

Such permeable flow barriers may suffer failures for structural or functional reasons in the case of floods. Structural failure occurs when the barrier stability compromised, e.g., owing to insufficient foundation (Suda and Rudolf-Miklau, 2008). This can be prevented by scour mitigation measures and by a proper static assessment of the structure (Bezzola, 2008; Piton and Recking, 2016a; Suda et al., 2009). Functional failure occurs when the barrier does not work as desired (Hübl et al., 2005), e.g., when sediment retention is insufficient or when previously deposited material is remobilized in undesired quantities during floods. This remobilization is subsequently referred to as unwanted sediment flushing. The functional failure depends on the sediment deposition control provided by the permeable barrier, which can be (Piton and Recking, 2016a)

\footnotetext{
Corresponding author.

E-mail address: sebastian.schwindt@epfl.ch (S. Schwindt).
} 
- Hydraulic control, i.e., the bedload transport capacity of the channel reduces caused by backwater of the permeable barrier; or

- Mechanical control, i.e., the size of the transported objects in the shape of sediment or driftwood exceeds the clearance of the opening (s) of the barrier.

Hydraulic control is usually achieved by barriers with slits or slots. Slits are lateral flow constrictions with free surface flow, and slots are vertical flow constrictions with pressure flow conditions. The hydraulic control has been found to depend on the flow conditions in the backwater of the constriction-like barriers and on the channel slope (Schwindt 2017).

The reliable application of hydraulic control barriers can be achieved through adjustable opening sizes, e.g., by weirs equipped with gates, such as that at the Schächen torrent in Switzerland or the Schnannerbach torrent in Austria (die.wildbach, 2016; Kanton Uri, 2016). However, the installation of adjustable openings (or orifices) in the barrier requires vulnerable mechanical equipment (gates), triggering devices for hydraulic controls, and permanent standby duty that are cost-intensive in remote alpine regions. The decision making for triggering gate operations requires the definition of threshold values in terms of the river discharge. The operation of gates may be particularly difficult in the case of extreme flood events or when driftwood blocks the weir. To the authors' best knowledge, guidelines for gate operations are not part of any legal framework. Thus, the answer to the question concerning the responsibility for damages downstream of adjustable measures is a contentious issue. Because of the high costs and the legal implications of adjustable weir openings, alternative, passively working solutions are preferable.

Mechanical control is induced by barriers with multiple openings or screens where the narrower opening clearance dimension is decisive in clogging (Piton and Recking, 2016a). The geometric design criteria that lead to mechanically induced sediment deposition have been analyzed in previous studies. The probability of clogging is high when the clearance height or width of opening(s) is smaller than the characteristic dimensions of the transported objects, e.g., the representative grain diameter of the sediment. For clearance dimensions of twice this diameter or more, the clogging probability is low (e.g., Bezzola et al., 2004; Frey and Tannou, 2000; Ikeya, 1989; Piton and Recking, 2016a; Takahashi, 2014; Uchiogi et al., 1996; Wallerstein et al., 2013; Watanabe et al., 1980; Zollinger, 1983). The complete mechanical obstruction of a barrier is not prone to unwanted sediment flushing (selfemptying), but malfunction remains possible when the sediment size is smaller than expected (Hübl et al., 2006). Decreasing the effective flow clearance enhances the safety against unwanted sediment flushing - but undersized clearances may involve regular sediment deposits upstream of sediment check dams. This deposited sediment has to be frequently dredged and is lacking in downstream reaches, with negative effects on the river morphology (Brandt, 2000; Kondolf, 1997; Schleiss et al., 2014).

Thus, hydraulic and mechanical control measures have certain disadvantages. Both types and their combination are considered here to overcome negative consequences because of uncertainties related to insufficient or excessive sediment retention. In practice, the implementation of both control mechanisms is sometimes applied for the combined retention of driftwood and sediment, where a mechanical control barrier in the shape of a screen is designed based on the expected size of driftwood (Hübl et al., 2003). Some study cases for the combination of hydraulic and mechanical retention of bedload exclusively can be found (Piton and Recking, 2016b; Schwindt et al., 2016), but the systematic experimental study as made herein is novel.

The main objective of this research is to investigate the sediment transfer at barriers designed for hydraulic or mechanical control and of barriers that combine both types of controls. Sediment transfer is exclusively considered in terms of bedload. Thus, the mitigation of debris flow and woody debris-related hazards, which may require additional structures upstream of the herein considered barriers, are not addressed in the present study.

The particular interest of this study is the conception of barriers to enable fluvial bedload transport until some threshold discharge is exceeded. For higher discharges, bedload should be retained without the possibility of being remobilized, i.e., to prevent unwanted sediment flushing. The results from previous studies are considered for the reference bedload transport in the channel without barriers and without sediment deposits (Schwindt, 2017; Schwindt et al., 2017). In contrast and complementary to these previous studies, the formation of deposits upstream and overflow of the barrier are investigated.

\section{Methodology}

\subsection{Experimental setup}

A database with 132 field observations on mountain rivers, partially furnished with sediment check dams, was used for the design of the experimental setup (Schwindt et al., 2017). As shown in Fig. 1, the observation area of the setup consisted of a steep, open channel where water and sediment were supplied at the upper boundary.

An automated sediment supply system composed of a cylindrical container, for the storage of sediments and with a bottom screw to release the grains on a system of conveyor belts, was used. The grain size distribution of the sediment supply was characterized by the following parameters: $D_{16}=7.3 \mathrm{~mm}, D_{50} \approx D_{m}=10.4 \mathrm{~mm}$ and $D_{84}=$ $13.7 \mathrm{~mm}$. Water was supplied by a laboratory pump system, with discharge $Q$ varying between 3.0 and $10.0 \mathrm{l} / \mathrm{s}$. Sediment and water were intermixed in an upstream adaptation reach. The 2.5-m-long adaptation reach ended in a 3.0-m-long observation reach, with a rough trapezoidal bottom and a longitudinal slope of $S=5.5 \%$. Check dams consisting of hydraulic or mechanical control barriers were introduced in the lower third (Fig. 1). The trapezoidal channel cross section was characterized by a bottom width of $w \approx 0.11 \mathrm{~m}$ and a bank slope of $m \approx$ 2.25:1 (Fig. 2A). The rough surface of the channel consisted of grains cast in mortar with the size of the $D_{84}$ of the supply mixture or larger, as a representative grain size for roughness (Ferguson, 2007; Ghilardi et al., 2014; Rickenmann and Recking, 2011; Zimmermann, 2010). The water-sediment mixture was separated at the downstream model end by a filter basket. The collected sediments were redirected to the sediment container by an overhead crane. The outflowing water returned to the laboratory pump well.

The sediment input rate was controlled by the rotational speed of a perforated cylinder at the bottom of the sediment container. The bedload transport $Q_{b}$ was evaluated at the outlet by minute-wise weight measurements of the outflowing sediment using a scale (type Dynafor MWXL-5, precision of $\pm 0.01 \mathrm{~kg}$ ). The flow rate $Q$ was measured by a flow meter (type ABB FXE4000) with a precision of $0.1 \%$. The flow depth $h$ along the observation reach was gauged by five ultrasound probes, of which four were situated upstream of the deposition control barrier and one was situated downstream. The ultrasound probes (type Baumer UNAM 30) have a precision of $\pm 1 \mathrm{~mm}$ and were placed with an interspace distance of $\sim 0.4 \mathrm{~m}$. The channel cross section geometry at the position of every ultrasound probe was derived from point-cloud measurements with a laser (type Leica DISTO D410, precision of \pm 1 $\mathrm{mm})$.

\subsection{Sediment deposition control}

The occurrence of sediment deposition imposed by flow barriers is subsequently related to the occurrence of ordinary and exceptional flood events (Lenzi et al., 1999). With respect to morphological river continuity, deposition control barriers should not affect the bedload transport for ordinary floods (Schleiss et al., 2014). These ordinary floods vary from case to case and can be referred to as a morphologically effective discharge (Wolman and Leopold, 1957a,b; Wolman and 


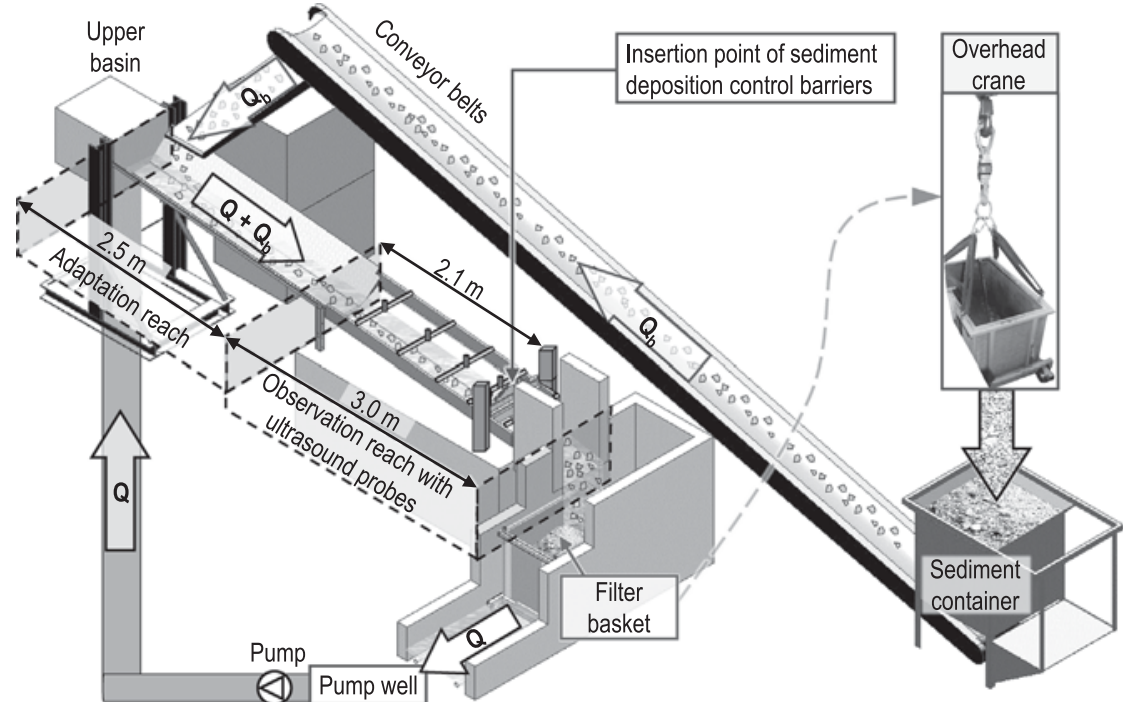

(A) View from upstream

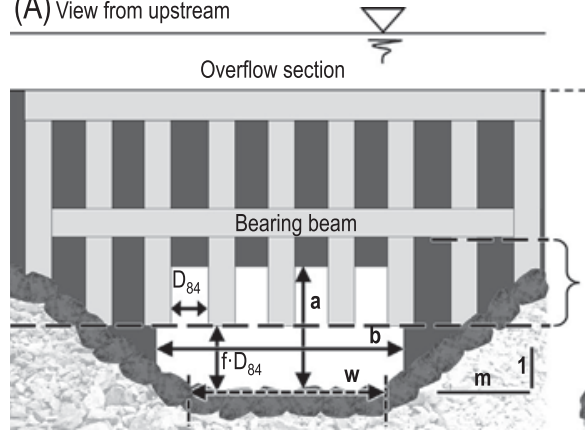

(B) Longitudinal section

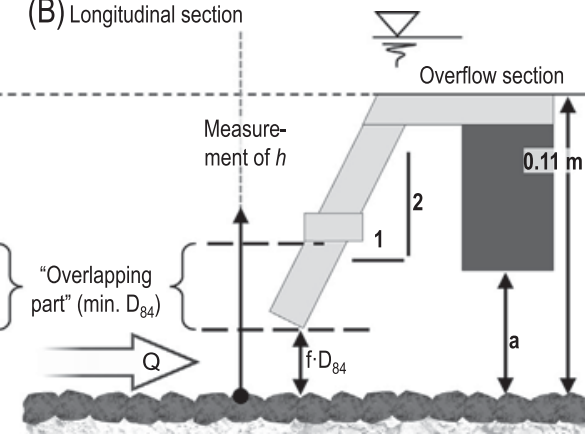

Fig. 1. Conceptual sketch of the model, with the sediment supply system consisting of a sediment container with bottom screw and conveyor belts; sediment and water were mixed in an upstream adaptation reach, which ends in the main observation reach. The flow control barriers were introduced in the lower third of the observation reach; a filter basket, which was suspended on an overhead crane with a scale, provided the separation and weighing of the outflowing sediment.
Miller, 1960), which is essential for the channel bed morphology. Discharges that are subsequently labeled as exceptional refer to floods that endanger urban areas over the river banks. For the present experiments, the differentiation between ordinary (smaller) and exceptional (higher) discharges is abstracted in terms of some dimensionless parameters. The essential point for the experiments is that there are certain small discharges at which sediment transfer is possible and exceptional discharges at which sediment is retained.

Hydraulic control barriers with vertical and lateral flow constrictions were analyzed by the help of mobile PVC elements imposing a flow constriction, with height $a$ and width $b$ (dark gray elements in Fig. 2). The description of the upstream hydraulics requires the differentiation between pressure (vertical constriction) and free surface (lateral constriction) flow conditions in the constriction (Schwindt 2017). For hydraulic control, experiments were conducted without and with overflow of the barrier crest.

The conception of mechanical control devices was related to the grain size of the transported sediment, according to traveling bedload in nature (Piton and Recking, 2016a). This type of bedload transport may be characterized by the grain size distribution of sediment deposits from former floods at the banks of the upstream channel.

An inclined bar screen (or trash rack) with cylindrical bars (inclination of 2:1, light gray elements in Fig. 2) was applied for mechanical control. The inclination of the bar screen favors the sliding and passage of potentially occurring driftwood over the structure when it is overflown. Thus, the risk of unwanted driftwood accumulations and the obstruction of the screen are reduced. In practice, additional structures for driftwood retention should be considered (Bezzola et al., 2004; Lange and Bezzola, 2006; Piton and Recking, 2016b). The design of the mechanical control barrier in the present study was based on the size of the transported sediment, not in direct dependence on the discharge, according to literature findings (Ono et al., 2004; Piton and Recking, 2016a; Shima et al., 2016). Based on these previous findings, the clearance height between the channel bottom and the lower end of the vertical bars was determined as a multiple $f$ of the representative grain size $D_{84}$ (Fig. 2). Small clearance heights $(f<1.5)$ were expected to cause sediment deposition as soon as sediment is supplied to the flume. However, with regard to the continuity of sediment transport, which is ecomorphologically preferable (Piton and Recking, 2017; Simoni et al., 2017), the retention of small bedload transport rates is not appropriate. Therefore, small clearance heights of $f<1.5$ are subsequently not considered. However, the clogging of the screen is advantageous to ensure complete mechanical sealing in the case of intense bedload transport and thereby to avoid unwanted sediment flushing.

In this study, $f$ was tested incrementally, starting from $f \approx 1.5$, to assess the optimum clearance height, which is defined as the maximum height $f_{\text {opt }} \cdot D_{84}$ that can cause sediment deposition. This optimum clearance is related to the possibility of sediment transfer for ordinary (smaller) discharges and the safe occurrence of mechanical barrier clogging for exceptional (higher) discharges. The herein considered principle of mechanical clogging focuses on the trapping of bedload occurring with exceptional floods, where the active bedload layer is thicker than during smaller, ordinary discharges (Church and Haschenburger, 2017; Du Boys, 1879). The entangled grains cause an additional resistance to the flow, which causes the further retention of grains.

Therefore, the maximum bedload transport that can pass through the mechanical barrier (bar screen), without the entanglement of grains 


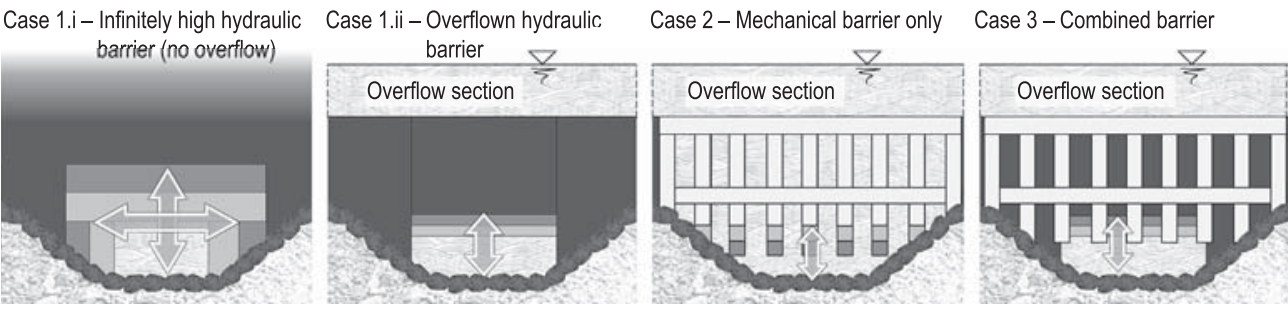

indicate effective flow sections of the barrier.
Fig. 3. Conceptual sketch of the barriers analyzed in this study: (1.i) infinitely high hydraulic barriers, with varying constriction width and height; (1.ii) simultaneously over- and underflown hydraulic barriers, with varying constriction height (hydraulic control only); (2.) bar screens only, for the optimization of the clearance height under the screen (mechanical control only); and (3.) combination of the bar screen superposed to the hydraulic barrier, with varying constriction height. The hatched areas between the bars, was tested for several pairs of constant discharge and incrementally increasing sediment supply. In this process, for a fixed discharge, the sediment supply was increased stepwise until the screen was mechanically clogged. The highest supply rate that did not yet lead to the clogging of the bar screen was then taken as the maximum bedload transport corresponding to the fixed discharge and to a certain barrier configuration. The bedload transport was measured as explained above. This procedure was repeated three times and the average value of the maximum bedload transport was taken. The barrier clogs instantaneously for solid discharges that are higher than the maximum bedload transport capacity. This analysis served for the identification of an optimum value for the clearance in terms of $f_{\text {opt }}$, which is high enough to not interfere with bedload transport for small discharges but low enough to enable mechanical clogging for higher discharges. The steady discharge refers to different flood stages, where in practice instantaneous quasi-steady flow conditions for the triggering of bedload retention may be admitted.

The horizontal spacing between the bars is chosen to be equal to $D_{84}$ to ensure clogging for higher discharges (Piton and Recking, 2016a,b; Uchiogi et al., 1996; Wallerstein et al., 2013). As required for prototype applications, an additional horizontal bearing beam was installed for the support of the vertical bars, which had no influence on the functioning of the barrier in the experiments.

Preliminary tests showed that the overlapping part of the vertical bars, beneath the bearing beam (Fig. 2), was essential for enabling the mechanical clogging. The jumping grains of the bedload became entangled between these free ends of the vertical bars. This entangling required a minimum overlapping length according to the $D_{84}$.

Sediment retention because of hydraulic control by flow constriction and mechanical control by the bar screen was tested individually and in combination. The transversal and longitudinal sections are schematically illustrated in Fig. 2. The tests related to purely hydraulic control were conducted twice: (i) with a quasi-infinite barrier height (no possibility of overflow) and (ii) with a limited barrier height of $0.11 \mathrm{~m}$, which corresponded to $8 \times D_{84}$. The height of the screen was not considered as a factor for mechanical clogging and was maintained as constant at $0.11 \mathrm{~m}$. The overflow section was $0.23 \mathrm{~m}$ wide. The location of flow depth measurements is qualitatively indicated in Fig. 2.

\subsection{Parameters and dimensional analyses}

The phenomena considered in this study may be described by the following set of parameters:

$\Lambda=a, b, D, f, g, h, S, m, Q, Q_{b}, w, \nu, \rho_{f}, \rho_{s}$

where $D$ is the representative grain size that is subsequently determined by the $D_{84}$ of the sediment supply mixture; $g$ is the gravitational acceleration $\left(9.81 \mathrm{~m} / \mathrm{s}^{2}\right) ; \nu$ is the kinematic viscosity of water, considered at $20^{\circ} \mathrm{C}\left(10^{-6} \mathrm{~m}^{2} / \mathrm{s}\right)$; and $\rho_{f}$ and $\rho_{s}$ denote water density $\left(1000 \mathrm{~kg} / \mathrm{m}^{3}\right)$ and sediment grain density $\left(2680 \mathrm{~kg} / \mathrm{m}^{3}\right)$, respectively. Because the focus of this study is on bedload transport, the dimensionally independent variables of $D_{84}, g$, and $\rho_{f}$ are used for the derivation of the following dimensionless parameters (Einstein, 1950; Yalin, 1977):
- $a_{*}=a / D_{84}$, grain-related opening height of vertical flow constrictions;

- $b_{*}=b / D_{84}$, grain-related opening width of lateral flow constrictions;

- $f$, factor of $D_{84}$ for the clearance height under the bar screen;

- $h_{*}=h / D_{84}$, relative flow depth upstream of the hydraulic control barrier;

- $F_{*}=Q /\left(A \cdot \sqrt{g D_{84}}\right)$, grain-related flow velocity;

- $s=\rho_{s} / \rho_{f}$, density ratio; and

- $\Phi=Q_{b} /\left(w_{m} \cdot \rho_{f} \cdot \sqrt{(s-1) g D_{84}^{3}}\right)$, (maximum) intensity of bedload corresponding to transport capacity conditions.

The term $A=h \cdot w_{m}$ denotes the flow cross section, where $w_{m}=w$ $+h \cdot m$ is the mean width of the trapezoidal channel (cf. Fig. 2). The hydraulic effects of the deposition control barriers on the upstream grain-related flow velocity $F_{*}$ are evaluated by relating the constriction height to the flow depth upstream of the barrier. Previous studies have shown that the constriction height $a$ is the governing geometric dimension for pressurized flow through hydraulic barriers. In the case of exclusively lateral constriction, the constriction width $b$ governs the upstream flow conditions (Schwindt, 2017; Schwindt et al., 2017). Therefore, the relative submergence is considered by $a_{*} / h_{*}$ and $b_{*} / h_{*}$ for vertical and lateral constriction by hydraulic control barriers respectively. The relation $f / h_{*}$, which is equivalent to $f \cdot D_{84} / h$, is applied for the assessment of flow conditions upstream of the bar screen for mechanical control only.

\subsection{Experiment design}

The bedload transport capacity is evaluated for three cases, with respect to the deposition control types, as illustrated in Fig. 3:

1. Sediment deposits upstream of the hydraulic control barriers (PVC elements) of

i. infinite barrier height (no overflow is possible), imposing flow constrictions with varying height $a$ and varying width $b$;

ii. limited barrier height (with overflow), imposing flow constrictions with varying height $a$ and constant width $b$;

2. Mechanical control barriers by a bar screen; and

3. Combination of hydraulic and mechanical controls.

In addition, this study refers to data from previous studies, where infinitely high barriers without upstream sediment deposits were analyzed (Schwindt 2017). The flow was generally supercritical in the steep rough laboratory channel (the Froude number varied between 1.4 and 1.9), similar to natural mountain rivers. Thus, barriers cause backwater, and a hydraulic jump occurs in the upstream. According to the literature (Armanini and Larcher, 2001; Campisano et al., 2014; Piton and Recking, 2016a), the hydraulically controlled formation of sediment deposits upstream of the barrier is initiated immediately downstream of this hydraulic jump. The additional volume of this sediment deposit provokes an increase in the length of the backwater and, in turn, causes a shift of the hydraulic jump in the upstream direction. Accordingly, for constant discharge, the location where bedload is 

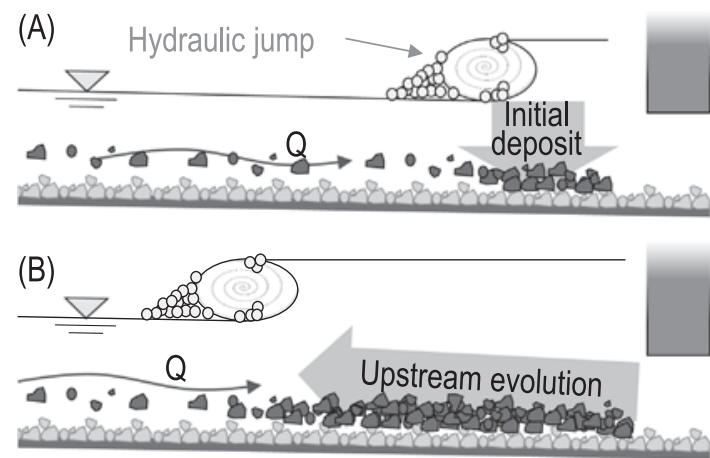

Fig. 4. Qualitative illustration of the evolution of an elongated sediment deposit upstream of an infinitely high barrier (case 1.i) with steady discharge and sediment supply: (A) at the beginning of an experiment, the sediment deposit occurs immediately downstream of the hydraulic jump, upstream of the barrier; and later (B) an upstream shift of the hydraulic jump is caused by the deposited sediment; progressively, the sediment deposit edge and the hydraulic jump move upstream.

deposited is also shifted in the upstream direction, as it is illustrated in Fig. 4. This formation of an elongated deposit evolving in the upstream direction occurs in case (1.i), for constant sediment supply and discharge, and infinitely high barriers. In case (1.i), sediment was supplied until the deposit reached the upstream boundary of the observation reach (cf. Fig. 1). Multiple combinations of constriction heights $a$ and widths $b$ were tested (Table 1 ).

The limitation of the barrier height prevents the upstream evolution of the backwater, which causes the deposit to evolve in the downstream direction. When the deposit front reaches the barrier, the formation of a secondary deposit layer can be expected on top of the previous deposit. Thus, the deposit evolves in a succession of quasi-equilibrium states until it reaches the barrier height (Armanini and Larcher, 2001; Campisano et al., 2014; Jordan et al., 2003; Piton and Recking, 2016a). Such hydraulically controlled sediment deposition patterns upstream of permeable barriers occur in case (1.ii), also with a constant sediment supply and discharge but for overflown barriers. For case (1.ii), the barrier height was limited to $0.11 \mathrm{~m}$, according to the above statements (Fig. 2), with variable constriction height $a$ but with constant width $b$ (Table 1).

In cases (1.i) and (1.ii), the maximum sediment outflow rate, related to each of the tested constant discharges, was retained. These values refer to sediment flushing phases that occurred at the end or during the tests. Thus, the maximum sediment outflow rates represent peak values for bedload transport downstream of the tested barriers.

The second test series (case 2) served for the optimization of the bar screen. A particularity of the bar screen is a free space between the screen bottom and the channel bed. This bottom clearance height below the bar screen, defined as $f \cdot D_{84}$, was analyzed experimentally. An optimum value of $f_{\text {opt }} \cdot D_{84}$ was investigated to allow for sediment transfer for ordinary discharges and sediment retention for higher discharges. This optimum clearance height was retained for the following experiments.

The upstream flow conditions and the bedload transport through the combination of hydraulic (flow constriction) and mechanical (bar

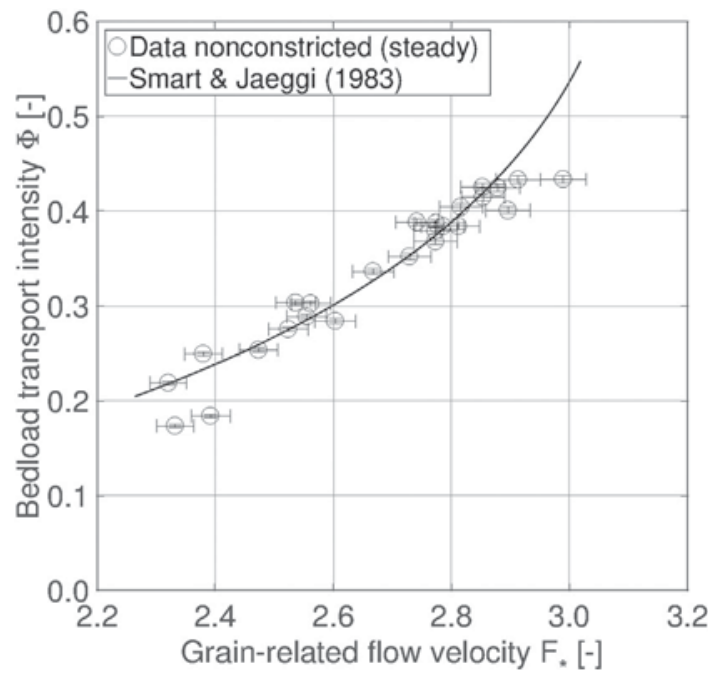

Fig. 5. Comparison of the measured bedload transport intensity in the nonconstricted channel, presented in Schwindt (2017), with results obtained with the formula from Smart and Jaeggi (1983).

screen) control constitute test case (3). For this combined control, the same constriction geometries were applied as for the hydraulic barrier only, with limited height (case 1.ii).

The experimental test cases, with the corresponding parameter combinations and types of deposition control, are summarized in Table 1.

\section{Results and analysis}

\subsection{Bedload transport without deposition control}

The evaluation of the so-called nonconstricted flow, i.e., channel capacity without barrier, was performed formerly by the authors (Schwindt, 2017; Schwindt et al., 2017) without considering sediment deposits. However, these experiments indicated that sediment transport through the barrier might increase when sediment deposits are present upstream of the constriction. For the present study, maximum bedload transport intensity $\Phi$ is represented in Fig. 5 as a function of the grainrelated flow velocity $F *$ instead of the discharge, as previously reported. The bedload transport intensity without sediment deposition control measures can be reproduced by the semiempiric formula from Smart and Jaeggi (1983), using the measured flow depth. Similar application cases for this formula can be found in previous studies (Sindelar et al., 2017). The flow in the nonconstricted channel was generally supercritical (Schwindt 2017).

The formula of Smart and Jaeggi (1983) refers to a mobile channel bed, where the bedload transport complies with the maximum transfer rate, corresponding to the hydraulic conditions in terms of the roughness, channel geometry, slope, and discharge. The formula is subsequently considered for the evaluation of the bedload transport capacity of the barrier-free flow.

Table 1

List of experiments for the determination of maximum bedload transport of barriers for hydraulic, mechanical, and combined deposition control.

\begin{tabular}{|c|c|c|c|c|c|c|c|c|c|c|}
\hline Number of experiments & \multicolumn{2}{|c|}{ Mechanical control } & \multicolumn{4}{|c|}{ Hydraulic control } & Barrier height & \multicolumn{2}{|c|}{ Discharge } & \multirow[t]{2}{*}{ Case } \\
\hline$[-]$ & $\begin{array}{l}f_{\min } \\
{[-]}\end{array}$ & $\begin{array}{c}f_{\max } \\
{[-]}\end{array}$ & $\begin{array}{l}a_{\min } \\
{[\mathrm{m}]}\end{array}$ & $\begin{array}{l}a_{\max } \\
{[\mathrm{m}]}\end{array}$ & $\begin{array}{l}b_{\min } \\
{[\mathrm{m}]}\end{array}$ & $\begin{array}{l}b_{\max } \\
{[\mathrm{m}]}\end{array}$ & {$[m]$} & $\begin{array}{l}Q_{\min } \\
{[l / s]}\end{array}$ & $\begin{array}{l}Q_{\max } \\
{[l / s]}\end{array}$ & \\
\hline 89 & \multicolumn{2}{|c|}{ none } & 0.047 & inf. & 0.10 & 0.14 & inf. & 5.0 & 10.0 & Case (1.i) \\
\hline 25 & \multicolumn{2}{|c|}{ none } & 0.040 & 0.047 & \multicolumn{2}{|c|}{0.15} & 0.11 & 6.0 & 10.0 & Case (1.ii) \\
\hline 87 & \multirow[t]{2}{*}{1.54} & 1.90 & \multicolumn{2}{|c|}{ none } & \multicolumn{2}{|c|}{ none } & 0.11 & 3.1 & 8.8 & Case 2 \\
\hline 85 & & $f_{o p t}$ & 0.040 & 0.047 & \multicolumn{2}{|c|}{0.15} & 0.11 & 3.2 & 8.6 & Case 3 \\
\hline
\end{tabular}



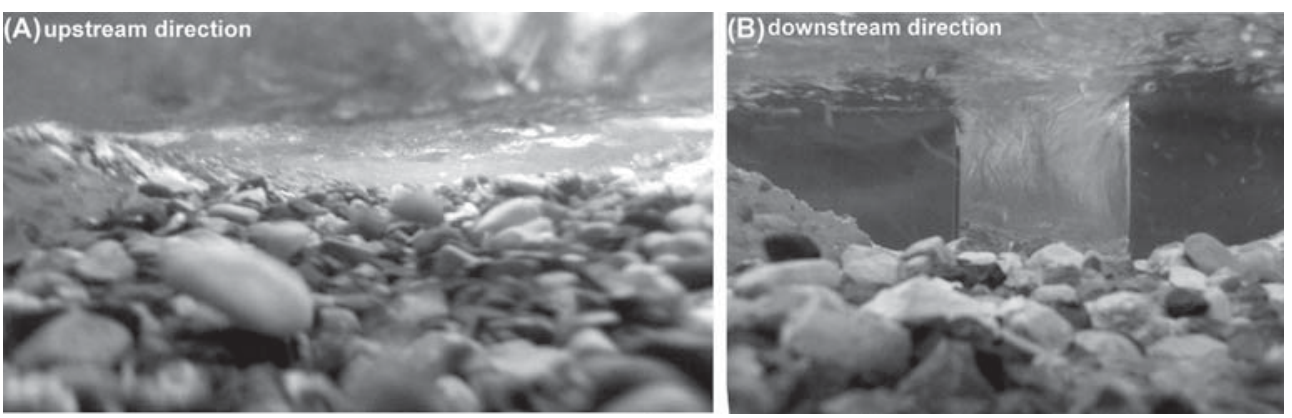

Fig. 6. Flat and elongated sediment deposits upstream of an infinitely high hydraulic barrier (case 1.i) at the end of an experimental run; view in the (A) upstream direction and (B) downstream direction toward the barrier.

\subsection{Hydraulic control (cases 1.i and 1.ii)}

The observed evolution of sediment deposits in the backwater of infinitely high barriers (no overflowing, case 1.i) is in good agreement with the descriptions from the literature (Armanini and Larcher, 2001; Campisano et al., 2014; Piton and Recking, 2016a). The sediment deposits caused an increase in the backwater upstream of the barrier. With increasing backwater, the hydraulic jump (and therefore also the tail of the deposit) moved in the upstream direction without further evolution of the deposit front. As reported in the literature (Campisano et al., 2014; Piton and Recking, 2016a; Fig. 4), this results in the formation of elongated sparse deposits, as illustrated in Fig. 6 by the underwater pictures. When the backwater tail reached the upstream model limit (corresponding to a limitation of the setup in terms of the observational length), the experiments were stopped. This procedure is similar to earlier experiments on sediment traps (Zollinger, 1984).

The typical evolution of the sediment deposit in the study case (1.ii), i.e., overflow of a hydraulic barrier with a limited height of $0.11 \mathrm{~m}$, is illustrated in Fig. 7 through topview pictures. First, the supplied sediment started to deposit upstream of the hydraulic barrier (Fig. 7A). Similar to the previous experiments without barrier overflow, the deposit evolved in the upstream direction. However, when the tail of the

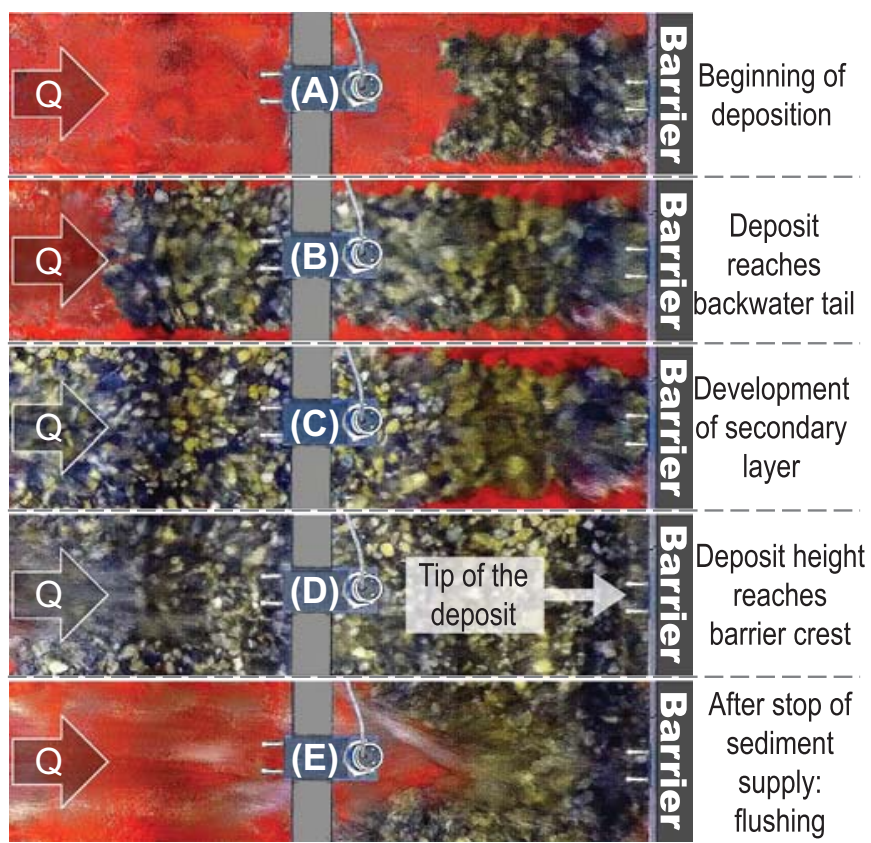

Fig. 7. Topview showing the temporal evolution of sediment deposits over the channel bottom (in red), upstream of hydraulically controlled barriers, with structure overflow (case 1.ii): (A) first deposit; (B) beginning of the secondary deposit layer; (C) evolution of the secondary layer from upstream toward the barrier; (D) maximum deposit size, immediately before flushing occurs; and (E) flushing. In the middle of each picture, one ultrasound probe with support structure is visible. The barrier is hidden by another ultrasound probe. deposit reached the end of the backwater reach of the barrier (Fig. 7B), a new deposit layer developed on top of the previous layer, as described in the literature (Fig. 7C; Campisano et al., 2014). This process repeated until the height of the deposit reached approximately the same height as the barrier crest (i.e., $0.11 \mathrm{~m}$, Fig. 7D). Then, the sediment supply was stopped, while the discharge was kept constant. Thus, the ratio between solid and water discharge was reduced, i.e., the discharge was no longer saturated with sediment. This leads to an excess of the bedload transport capacity which potentially provokes sediment flushing (Zollinger, 1983). Preliminary experiments showed that supplying subsequently more sediment was not reasonable as this results in an evolution of the sediment deposit similar to the situation of non-overflown barriers. The sediment flushing began at the tip of the deposit (Figs. 7D and E) until the total emptying of the upstream channel. The discharge was constant throughout every experimental run.

The dimensionless bedload transport intensity $\Phi$ as a function of $F *$, without sediment deposits upstream of the hydraulic barriers, obtained previously by the authors (Schwindt 2017) is illustrated in Fig. 8A. $\Phi$ corresponds to the highest value of bedload transport that did not cause sediment deposition upstream of the hydraulic barrier as long as it was not overflown. In Fig. 8B, $\Phi$ is evaluated based on the experiments with sediment deposits upstream of infinitely high (case 1.i, no overflow) and height-limited, overflown (case 1.ii) barriers. For case (1.i), both vertical flow constrictions, with pressurized flow conditions, imposed by the constriction height $a$ and lateral flow constrictions with free surface flow conditions, imposed by the constriction width $b$, are represented. The bedload transport intensity $\Phi$ refers to the maximum sediment outflow rates that were measured downstream of the barrier during flushing episodes (Fig. 7). The maxima of $\Phi$, with barrier overflow (case 1.ii), are one order of magnitude higher than in the case of infinitely high barriers without overflow (case 1.i). However, the bedload transport intensity observed during the flushing episodes never exceeded the values observed without deposits (cf. Fig. 5).

The comparison of Fig. 8A and B shows that the maximum bedload transport intensity downstream of a hydraulic barrier without the occurrence of overflow is similar, considering or not the existence of upstream sediment deposits.

The grain-related flow velocity, defined as $F_{*}=Q /\left(A \cdot \sqrt{g D_{84}}\right)$, is used in Fig. 8 for the description of $\Phi$. The relation between them can be interpolated by regression curves (continuous lines) according to the following expressions.

- No deposit (Fig. 8A) $\rightarrow$ Infinite barrier height (Schwindt 2017) $\Phi=$ $0.061 F_{*}-0.027\left(R^{2}=0.88\right)$;

- With deposit (Fig. 8B) $\rightarrow$ infinite barrier height (case 1.i) $\Phi=0.042$ $F_{*}-0.014\left(R^{2}=0.68\right)$; $\rightarrow$ limited barrier height (case 1.ii) $\Phi=$ $0.281 F_{*}-0.114\left(R^{2}=0.79\right)$.

The regression curves indicate that bedload transport, here represented by $\Phi$, occurs when $F_{*}$ exceeds the absolute values of the constant term, i.e., $F_{*} \geq 0.33$ in case (1.i) and $F_{*} \geq 0.25$ in case (1.ii). These thresholds, i.e., the constant terms, may be considered as critical values of $F *$ for sediment deposition when $F *$ is smaller than this. These 

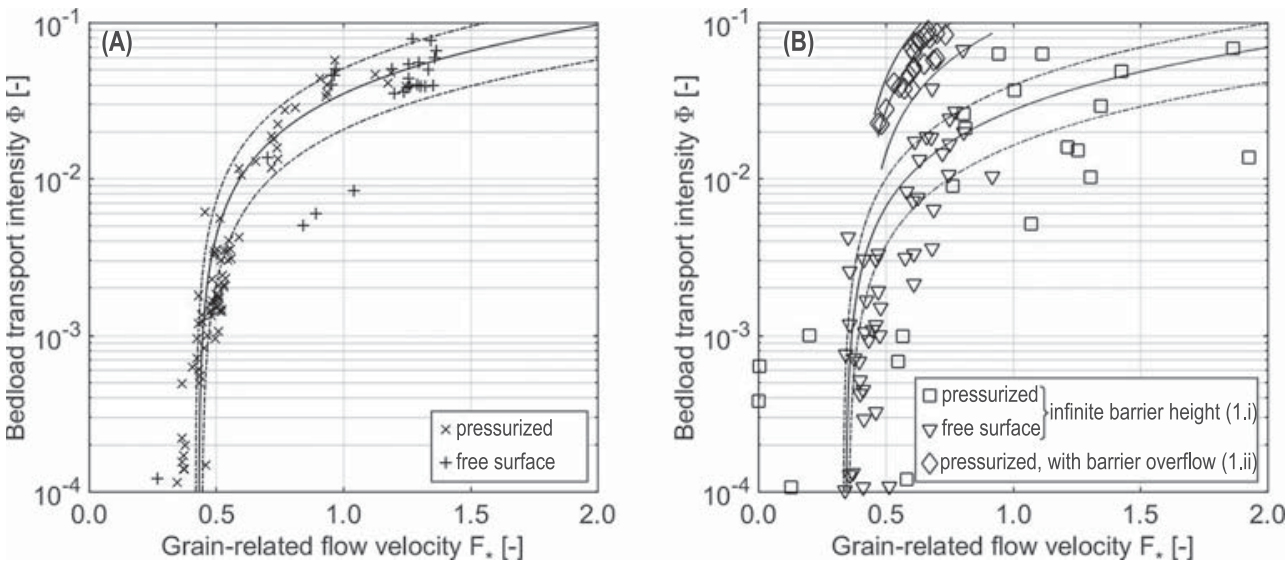

Fig. 8. The bedload transport intensity $\Phi$ as a function of the grain-related flow velocity $F_{*}$ (A) without (Schwindt 2017) and (B) with sediment deposits upstream of the hydraulic control barriers with infinite height (case 1.i, no overflow) and with limited height (case 1.ii, with overflow). Regression curves (continuous lines) are indicated with $68 \%$ confidence intervals (dashed lines).

observations refer to subcritical flow conditions (Froude numbers of $\sim 0.2$ to 0.3 ).

In theory, grain mobility in the backwater of hydraulic barriers can be assessed using the grain-related dimensionless bed shear stress $\tau_{*}$. Grain deposition is likely to occur when $\tau_{*}<\tau_{*, c r}$, where $\tau_{*, c r}$ denotes a critical value of $\tau_{*}$ (Einstein, 1950; Shields, 1936). The value of $\tau_{*, c r}$ increases with the channel slope and can be assessed for gravel-bed rivers by $\tau_{\star, c r}=0.15 S^{0.25}$ according to Lamb et al. (2008). Recking (2013) proposed an alternative expression that also implies the representative grain size $D_{84}: \tau_{*, 84, c r}=(1.32 S+0.037)\left(D_{84} / D_{50}\right)^{-0.93}$. For this study, the expressions from Lamb et al. (2008) and Recking (2013) resulted in $\tau_{*, c r}$ values of 0.73 and 0.67 respectively. For steady and uniform flow, the dimensionless bed shear stress can be computed by $\tau_{*}=h \cdot S /(s-1) D_{84}$ (Kramer, 1932; Von Karmàn, 1930). The measurements in the nonconstricted channel, corresponding though to the onset of sediment deposition, correspond to values of $\tau_{\star}, c r=$ $0.061 \pm 0.005$. It is highlighted here, that this value of $\tau_{*, c r}$ refers to the threshold for grain deposition, which was found to be smaller than $\tau_{\star, c r}$ for grain mobilization (Ancey et al., 2002). Hence, the smaller measurement values of $\tau_{*, c r}$ can be considered to be consistent with the literature and observations in natural streams. However, the flow in the backwater of the flow constrictions is not uniform, and the channel slope $S$ cannot be used instead of the energy slope. This evaluation, based on the friction law (Chézy, 1776), results in values of $\tau_{*, c r} \approx$ $0.04 \pm 0.005$ in the backwater of the hydraulic barriers (Schwindt et al., 2017).

The relationship between $F_{*}$ and the relative submergence of the orifice is assessed in Fig. 9. A clear and unique trend cannot be identified for pressurized orifice flow (Fig. 9A), in particular for case (1.ii) where overflow occurs. For free surface flow (lateral constrictions, Fig. 9B), clear linear trends between relative submergence $\left(b * / h_{*}\right)$ and grain-related flow velocity $F_{*}$ are observed corresponding to:
- No deposit (Schwindt 2017) $\rightarrow F_{*}=0.855 b_{*} / h_{*}-0.047\left(R^{2}=\right.$ 0.90); and

- With deposit (case 1.i) $\rightarrow F_{*}=0.37 b_{*} / h_{*}+0.049\left(R^{2}=0.86\right)$.

Accordingly, a clear and unique trend between $F_{*}$ and the relative orifice submergence $\left(a_{*} / h_{*}\right.$ and $\left.b_{*} / h_{*}\right)$ can only be identified in the case of solely laterally constricted, free surface flow (Fig. 9B). The relationship between $F_{*}$ and the relative submergence $a_{*} / h_{*}$ of vertical constrictions can be grouped by deposit allowances (Schwindt 2017, as well as data of cases 1.i and 1.ii; Fig. 9A). Some subgrouping can also be observed within the cases (1.i) and (1.ii), but the authors could not parametrize these subgroups based on the present data.

\subsection{Mechanical control (case 2)}

The effects of the bar screen on the upstream flow depth are evaluated in terms of the grain-related flow velocity $F_{*}$ as a function of the ratio $f / h_{*}$ (Fig. 10). The clearance height $f \cdot D_{84}$ under the screen was incrementally increased in millimeters. The normalized parameter $f / h$ * is used to relate the submergence of the barrier to the discharge, which is incorporated in the grain-related flow velocity $F_{*}$.

No clear trend between $f / h_{*}$ and $F_{*}$ can be observed in Fig. 10 . However, Fig. 10 allows one to estimate the flow resistance effects of the bars, which increases with decreasing clearance under the bars, i.e., decreasing $f$. The hydraulic effects of screens are commonly quantified by a local head loss coefficient as a function of the flow effective screen clearance, bar shape, and inclination (Di Stefano and Ferro, 2013, 2014; Hager, 2010).

The corresponding maximum bedload transport intensity $\Phi$ that could still pass the bar screen is shown in Fig. 11, related to $F_{*}$. These values were measured downstream of the bar screen, which clogged instantaneously under higher transport intensities compared to the
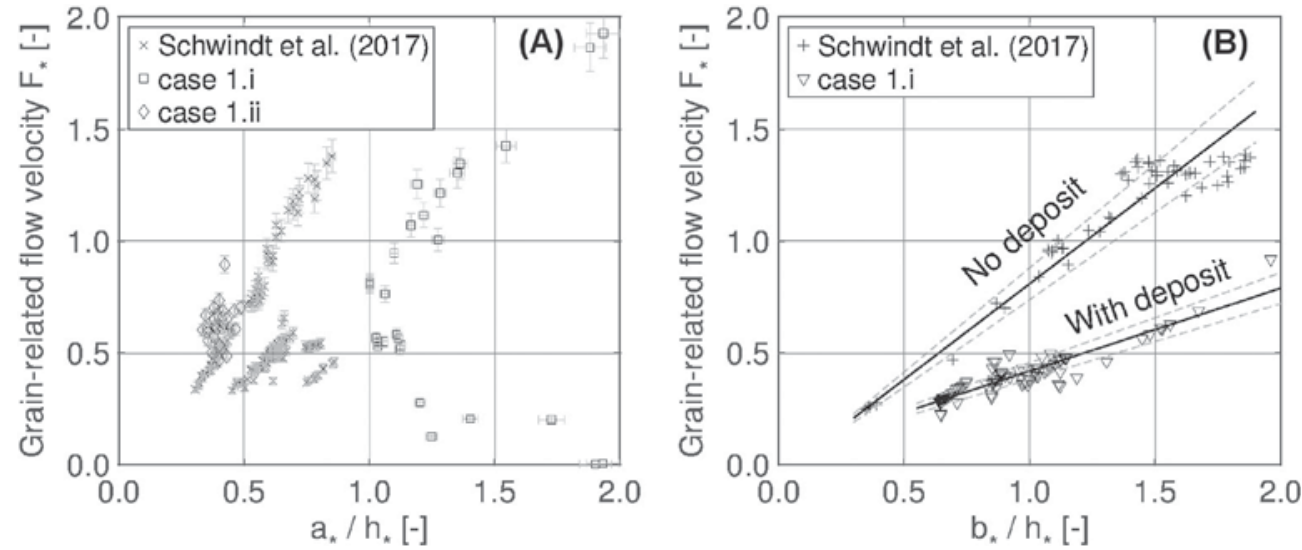

Fig. 9. Evaluation of grain-related flow velocity $F_{*}$ as a function of the relative submergence of hydraulic barriers with (A) vertical, pressurized $a_{*} / h_{*}$ and (B) lateral, free surface flow constrictions. The data from Schwindt (2017) corresponded to experiments neither with upstream sediment deposits nor with structure overflow; the new experiments correspond to case (1.i) with upstream deposit but without structure overflow; and case (1.ii) corresponds to upstream deposit and structure overflow. Regression curves (continuous lines) are indicated with $68 \%$ confidence intervals (dashed lines). 


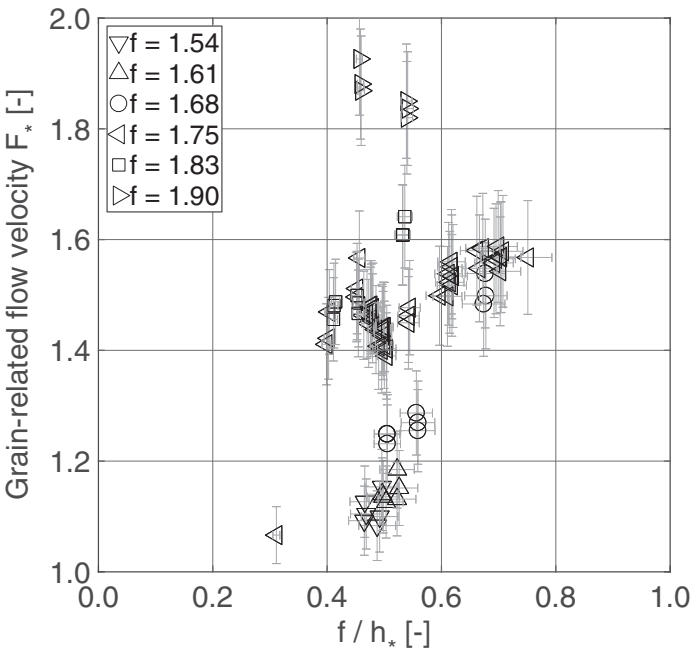

Fig. 10. Evaluation of grain-related flow velocity $F_{*}$ as a function of the relative submergence of mechanical barriers in terms of the bar screen, defined as $f / h^{*}=f \cdot D_{84} / h$ * (case 2, Fig. 3).

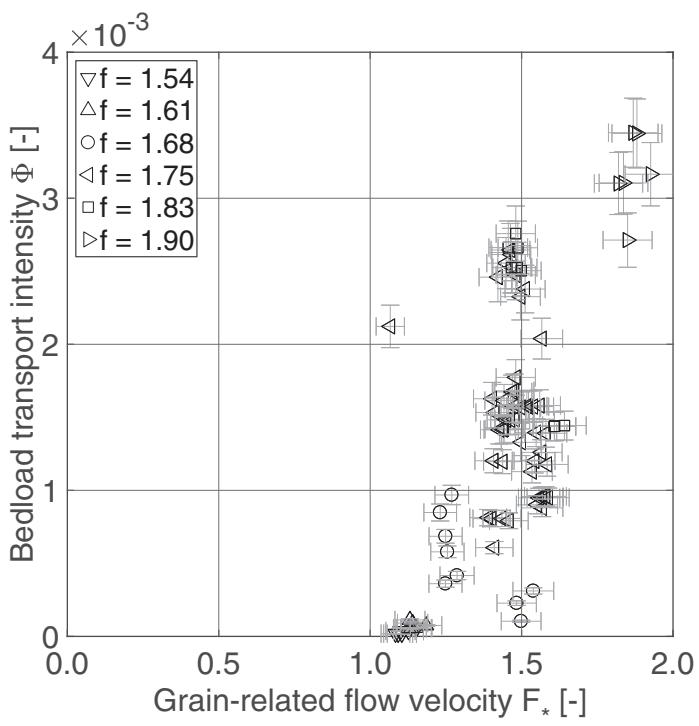

Fig. 11. The bedload transport intensity $\Phi$ as a function of the grain-related flow velocity $F_{*}$, with varying bottom clearance height $f \cdot D_{84}$ for mechanical barriers in terms of the bar screen (case 2, Fig. 3).

intensities shown in Fig. 11.

The values shown in Fig. 11 are grouped by $f$. The bar screen clogged quickly (lower values of $\Phi$ ) when $f<1.7$. For $f \approx 1.83$, clogging was only sometimes observed, and important bedload rates could pass the barrier under the higher discharges $\left(F_{*}>1.5\right)$. The bar screen was almost ineffective (clogging was very rarely observed) when $f$ was further increased $(f \approx 1.90)$. For $f \approx 1.75$, clogging was very probable for higher discharges $\left(F_{*}>1.5\right)$, whereas the bedload transport was not interrupted for ordinary discharges $\left(F_{*}<1.3\right)$. Thus, the desired bedload retention function of the mechanical barrier in terms of the bar screen was achieved at a value of $f \approx 1.75$. This value was retained for the subsequent experiments where the combined hydraulic and mechanical control was investigated.

\subsection{Combined control (case 3)}

The same experimental procedure was used for the combination of the hydraulic and mechanical control barrier as for the hydraulic

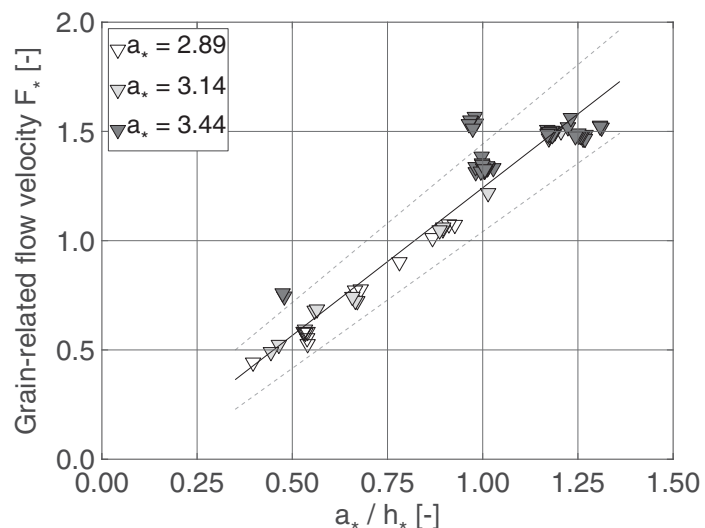

Fig. 12. Evaluation of the grain-related flow velocity $F_{*}$ as a function of the relative submergence $a_{*} / h_{*}$ for combined (hydraulic and mechanical) control barriers (case 3 , Fig. 3), for a constant value of $f_{\text {opt }}=1.75$, with varying constriction height $a$ and constant constriction width $b$. The regression curve (continuous line) is indicated with $68 \%$ confidence intervals (dashed lines).

control only. Thus, the barrier height, defining the level over which overflow occurs, was kept at $0.11 \mathrm{~m}$ (hydraulic and mechanical, cf. Figs. 2 and 3). Regarding the hydraulic control structure, a varying constriction height $a$ and a constant width $b$ were applied (case 1.ii, Fig. 3). The bar screen was placed with the optimum bottom clearance of $1.75 D_{84}$ according to the previous experiments (case 2). By definition, the hydraulic control barrier governs the hydraulics upstream of the barrier in terms of the constriction dimensions. Therefore, $F_{*}$ is shown in Fig. 12 as a function of the relative submergence of the hydraulic control $a_{*} / h_{*}$. This relationship can be interpolated by $F_{*}=1.35$ $a_{*} / h_{*}-0.11\left(R^{2}=0.89\right)$.

The bedload transport intensity $\Phi$ through the combined control barrier is shown in Fig. 13 as a function of the grain-related flow velocity $F_{*}$. The figure shows that the maximum values of $\Phi$ increase with increasing $F_{*}$ and with increasing relative constriction height $a_{*}$.

Once a deposit developed during the tests, the barrier was obstructed such that sediment flushing could not occur, as illustrated in Fig. 14.

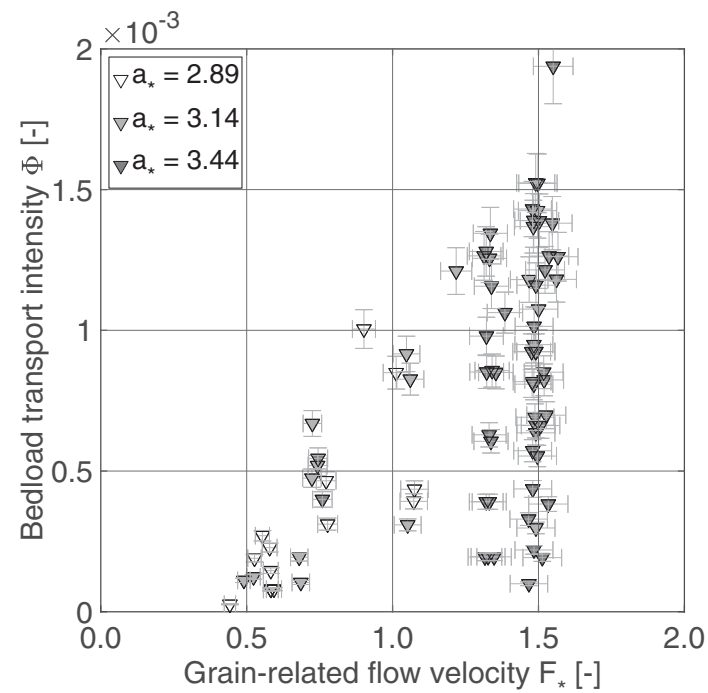

Fig. 13. The bedload transport intensity $\Phi$ as a function of the grain-related flow velocity $F_{*}$ for combined (hydraulic and mechanical) control barriers (case 3, Fig. 3), for a constant value of $f_{\text {opt }}=1.75$, with varying constriction height $a$ and constant constriction width $b$. 


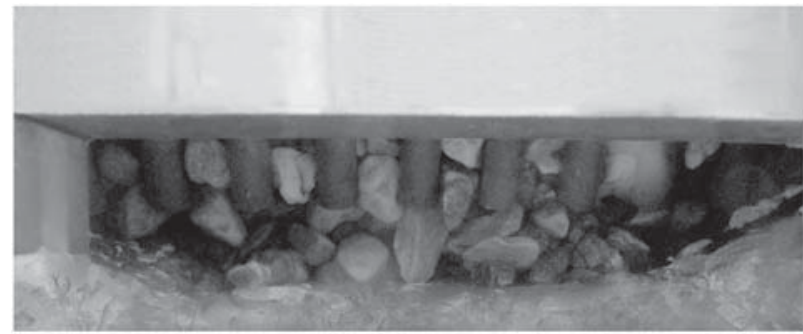

Fig. 14. Entangled grains at the combined (hydraulic and mechanical) control barrier (case 3, Fig. 3); cross sectional view from downstream.

\section{Discussion}

The grains used in the present experimental work were rather coarse $\left(w / D_{84} \approx 8.0\right)$. However, finer sediment is also expected to deposit with the reduction in flow transport capacity that reduces in the backwater of the hydraulic barrier.

Related to hydraulic control, the description of upstream flow conditions is based on flow depth measurements made in the vicinity of the barriers. This is possible because the sediment deposit never interacted directly with the barrier, i.e., the measured flow depth always refers to the clear water depth over the channel bottom.

The flushing of sediment deposited upstream of the barrier was not possible once the bar screen was clogged. However, sediment transfer without barrier clogging is desirable for ordinary discharges (Simoni et al., 2017; Surian and Rinaldi, 2003). The optimum value of $f_{\text {opt }} D_{84}=$ $1.75 D_{84}$ for the bottom clearance of the screen (Fig. 2) is sensitive to the sediment grain size, and other studies have reported slightly different values of $f$ for the occurrence of clogging (Canelas et al., 2015; Lien, 2003; Mizuyama, 2008; Ono et al., 2004; Piton and Recking, 2016a; Uchiogi et al., 1996; Zollinger, 1983). In this study, the measurement inaccuracy of $f$ is approximately \pm 0.07 , i.e., $f=1.75 \pm 0.07$, within a $68 \%$ confidence interval. This overlaps with the values of $f$ that correspond to experimental observations of more prompt $(f=1.68)$ or rare $(f=1.83)$ clogging. Therefore, the design of barriers for mechanical control requires special attention in practice, as there are often uncertainties regarding sediment size; also driftwood, which is not considered by this study, may occur.

Unwanted flushing of sediment deposits upstream of hydraulic control barriers represents a major problem in practice. Herein, three practical cases of sediment deposition control structures are discussed vis-à-vis the experimental results. The flushing of sediment deposits is of particular interest in these practical cases, which are the following:

- The previous barrier of Stiglisbrücke at the Schächen torrent (Canton of Uri, Switzerland), which consists of a slit check dam (opencrested torrential barrier with narrow vertical orifice, i.e., lateral flow constriction) with horizontal beams in the orifice (Bezzola, 2008);

- The slot check dam (close-crested torrential barrier with wide and low openings) at the headwaters of the Schnannerbach torrent in the Tyrol (Austria, Fig. 15); and

- The filter check dam (Fig. 16A) at the Drance torrent (close-crested sill with one opening in the Canton of Valais, Switzerland) with an upstream superposed bar screen, which was previously studied by the authors through physical model experiments (Schwindt et al., 2016).

In the case of the Schächen torrent, the Stiglisbrücke barrier was filled up and flushed out several times during a major flood in August 2005 (Püntener, 2006). The main cause for the unwanted sediment flushing of Stiglisbrücke was temporary scour of the unpaved bottom outlet and the downstream stilling basin. But the final results of the flushing processes at Stiglisbrücke were similar to the phenomena

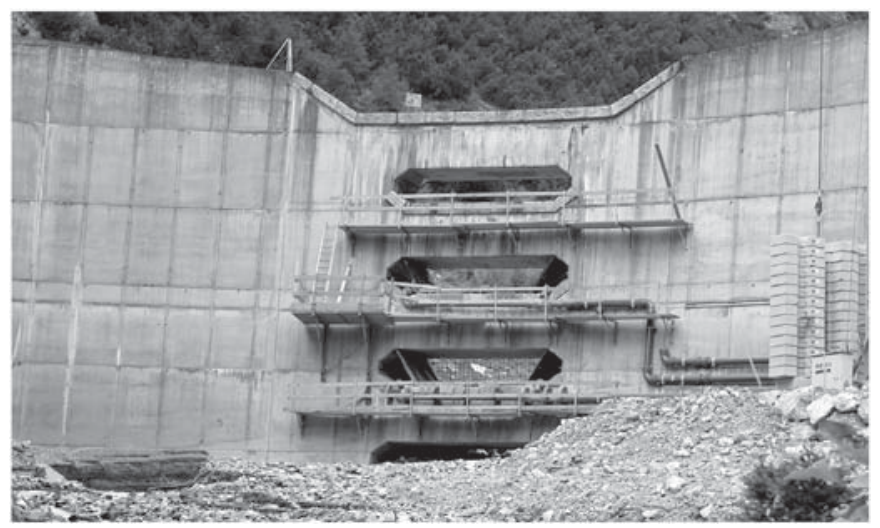

Fig. 15. Picture of the slot barrier at the Schnannerbach torrent (Austria) after the flood event in August 2005; view from downstream (source: Michael Sturm, Uni Innsbruck, with permission).
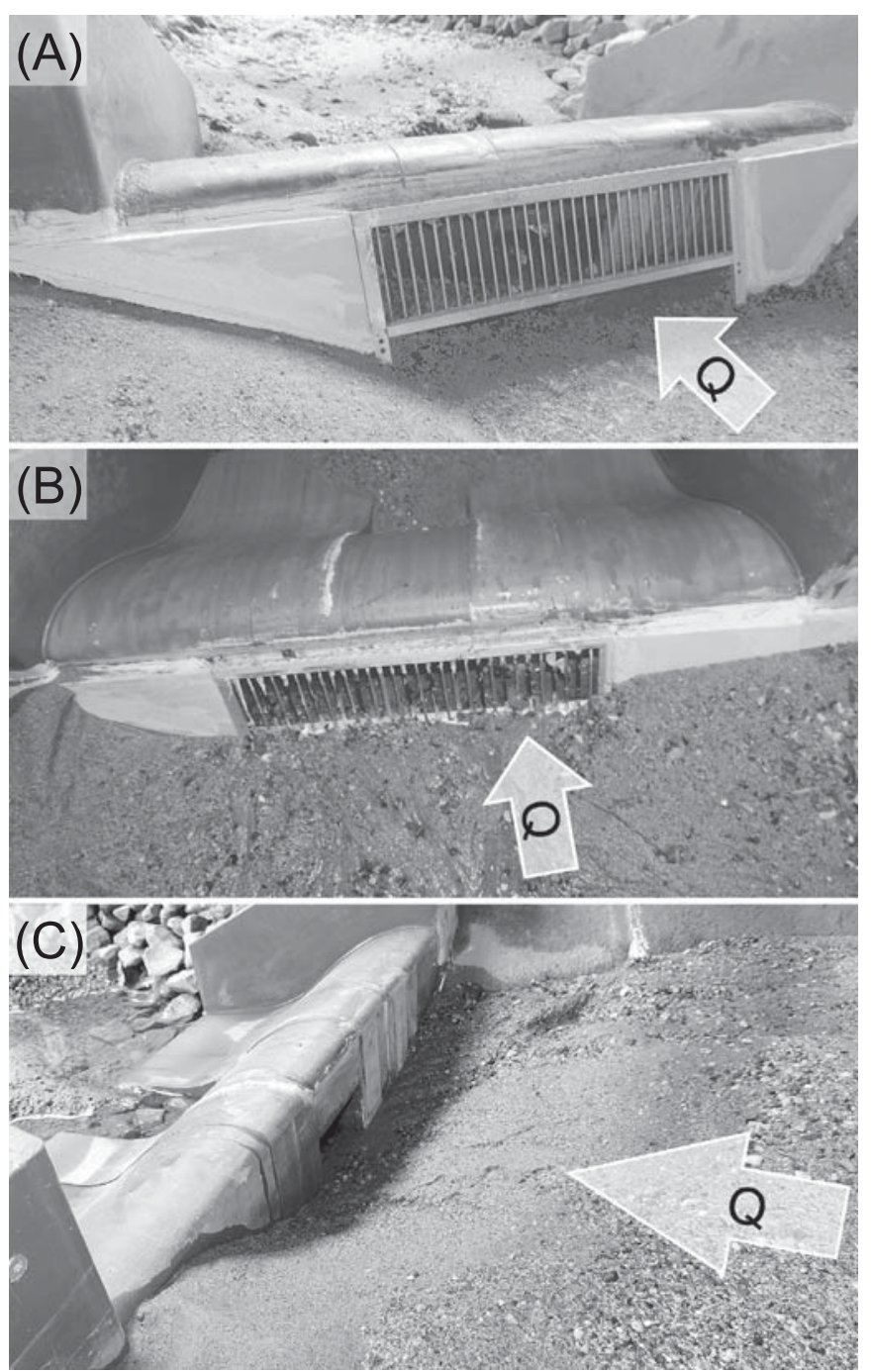

Fig. 16. Model of the sediment check dam at the Drance torrent (Schwindt et al., 2016); (A) the barrier composed of an inclined bar screen (mechanical control) upstream of a massive structure with a slot for hydraulic control, (B) mechanical obstruction of the upstream screen after the arrival of the sediment front, and (C) aspiration cone in the sediment deposit upstream of the barrier without the screen (source: Sebastian Schwindt orcid $=$ "0000-0002-7206-0542").

described in the present study, corresponding to Fig. 7, for overflown hydraulic control barriers. Although Stiglisbrücke was primarily 
designed for mechanical control, the process analysis of the 2005 flood event indicates that the barrier did not clog mechanically and therefore acted similar to an insufficient hydraulic control measure (Bezzola, 2008). This underlines the necessity of the consideration of the hydraulic control of such slit check dams. The Stiglisbrücke barrier was remodeled using a robust mobile weir that currently serves for adjusting the height of one opening in the now close-crested barrier (Kanton Uri, 2016). This constitutes an adjustable hydraulic control measure. However, this is a cost-intensive solution that requires regular maintenance works and standby duty on site in case of floods. As mentioned in the introduction, the legal framework and responsibility of triggering weir adjustments cause further implications. Therefore, it is advantageous to substitute such adjustable technical solutions with passive measures such as the presently studied combination of hydraulic and mechanical control.

During the same flood event in August 2005, the barrier at the Schnannerbach was also subjected to unwanted sediment flushing. This barrier is a massive concrete structure with multiple slots (Fig. 15). At the beginning of the flood, the barrier acted as desired and caused upstream sediment deposition. But at some unknown instant, sediment flushing occurred and caused important damage in downstream urban reaches. The sediment transport processes were described as fluvial bedload transport, without the occurrence of debris flow and woody debris (Hübl et al., 2006). In Fig. 15, one can observe that sediment size is significantly smaller than the opening size. Therefore, it is likely that the barrier acted exclusively as a hydraulic control measure.

These observations raise the question of whether an upstream superposed mechanical control barrier, as applied in the experiments in this study, can prevent unwanted sediment flushing even if the representative grain size is smaller than expected. Such a case was studied through physical experiments at the Drance torrent (Switzerland) using a physical Froude model of scale 1:42. One of the objectives of this study was the verification of the working principle of a filter check dam composed of an upstream superposed bar screen for mechanical control and a downstream slot for hydraulic control (Fig. 16A). This mechanical barrier was composed of vertical bars with an inclination of 2:1 and horizontal interspace corresponding to the $D_{84}$ of the supplied sediment. The bottom clearance height of the screen was set to $2.6 \cdot D_{84}$, but the vertical bars used in the Drance model did not overlap the bearing beam as in the present study (cf. Fig. 2). The experiments with the Drance model were conducted with constant water discharge and sediment supply for investigating hydraulic sediment retention and the obstruction of the barrier.

The formation of sediment deposits was observed in the backwater of the barrier. These deposits evolved slowly in the downstream direction toward the barrier. When the deposit front reached the barrier, the superposed screen was obstructed as shown in Fig. 16B. This obstruction was not observed for higher values of $f$ or without a mechanical control device, as shown in Fig. 16C (Schwindt et al., 2016). This shows that the sensitivity of clogging of mechanical barriers in terms of the grain size decreases in the backwater of hydraulic barriers because clogging is still possible for $f=2.6$. Without the backwater of the hydraulic barriers, clogging is not possible for $f>2$, as shown in the present study and according to literature findings (Lien, 2003; Mizuyama, 2008; Piton and Recking, 2016a; Shima et al., 2016; Uchiogi et al., 1996; Zollinger, 1983). In addition, the weak point of the hydraulic barrier, i.e., unwanted sediment flushing, was prevented by the upstream bar screen.

The comparison of Figs. 8B and 13 shows that the maximum bedload transport intensity $\Phi$ of overflown hydraulic barriers is approximately two orders of magnitude higher than in the case of overflown barriers with an upstream screen for mechanical control connected to a downstream hydraulic barrier. This analysis is based on the dimensionless grain-related flow velocity $F_{*}$, which is, for overflown structures, a linear function of the ratio of the relative constriction height and upstream flow depth (Fig. 12).

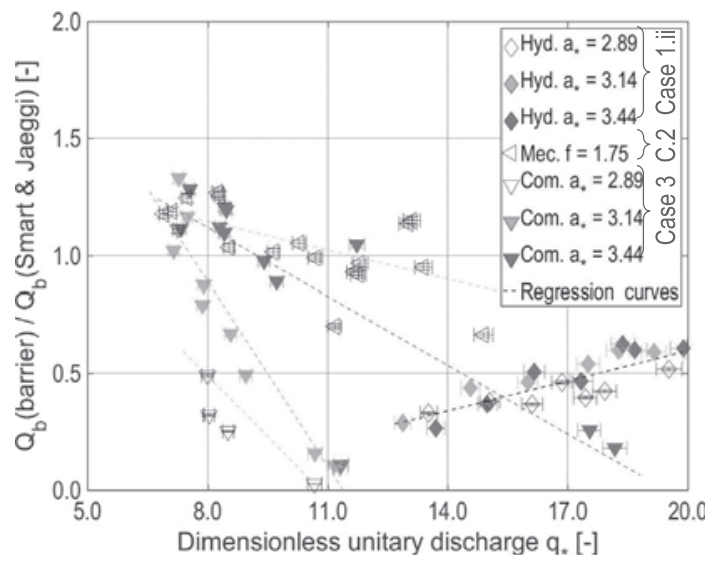

Fig. 17. Comparison of the ratio between bedload passing the barrier and bedload according to the Smart and Jaeggi (1983) formula as a function of the dimensionless unitary discharge $q_{*}$ (Eq. (2)) for overflown hydraulic, mechanical, and combined barriers. The dashed lines indicate regression curves (Table 2), and the error bars refer to the inaccuracy of the measuring equipment.

The establishment of discharge rating curves upstream of deposition control measures is, in practice, often impossible during floods caused by morphological changes, i.e., channel adjustments caused by temporal sediment deposition and remobilization (Piton, 2016). Thus, it might be useful to relate bedload retention exclusively to the dimensionless unitary discharge $q_{*}$, without the necessity of a discharge rating curve. With respect to the above dimensional analysis, $q_{*}$ is defined as:

$q_{*}=\frac{Q}{w} \cdot \frac{1}{\sqrt{g \cdot D_{84}}}$

The Smart and Jaeggi (1983) formula has been shown to be suitable for describing the reference bedload transport capacity $Q_{b}$ of the channel without barrier (cf. Fig. 5). Therefore, the measured bedload through the barriers is related in Fig. 17 to the theoretical value from the Smart and Jaeggi (1983) formula.

The Smart and Jaeggi (1983) formula overestimates the bedload transport of steep headwaters with limited sediment supply by approximately two orders of magnitude (Rickenmann, 2001). However, sediment deposits upstream of hydraulic barriers may represent an important sediment source in the case of sediment flushing. This may cause artificial debris flow, as observed, e.g., at Slovenian mountain rivers (Sodnik et al., 2015). According to the present study, such intense sediment transport may occur when hydraulic barriers transform typically supply-limited channels into channels with locally unlimited sediment supply (Recking, 2012). This difference in bedload transport between the Smart and Jaeggi (1983) formula and naturally supplylimited channels may represent a hazard to urban downstream river reaches, where the transport capacity can be reduced at bottlenecks such as bridges. The ratio of the bedload transport capacity with hydraulic, mechanical, or combined (mechanical plus hydraulic) barriers $Q_{b}$ (barrier) determined in the present study and by the Smart and Jaeggi (1983) formula $Q_{b}$ (Smart \& Jaeggi) is shown in Fig. 17 as a function of the discharge. When this ratio is unity, the bedload transported through the barrier corresponds to the bedload transport given by the Smart and Jaeggi (1983) formula. The coefficients of the linear regression curves (dashed lines) of the shape $p 1 \cdot q^{*}+p 2$ in Fig. 17 are listed in Table 2.

For hydraulic control, a single linear regression curve indicates that bedload transport capacity increases with discharge. According to the regression coefficients (Table 2), the bedload transport of the overflown hydraulic barrier is equivalent to the bedload transport estimated with the Smart and Jaeggi (1983) formula when $q_{*} \approx 30(Q \approx 14 \mathrm{l} / \mathrm{s})$. An additional test run with $q_{*} \approx 26(Q=12.3 \mathrm{l} / \mathrm{s})$ was performed to verify 
Table 2

Parameters of the linear regression curves in Fig. 17 with indication of the coefficients of determination $R^{2}$

\begin{tabular}{lllll}
\hline Case & Graph & $p 1$ & $p 2$ & $R^{2}$ \\
\hline 1. ii & Hyd. (all) & 0.043 & -0.26 & 0.72 \\
2 & Mec. $(f=1.75)$ & -0.041 & 1.47 & 0.42 \\
3 & Com. $\left(a_{*}=2.89\right)$ & -0.174 & 1.88 & 0.64 \\
3 & Com. $\left(a_{*}=3.14\right)$ & -0.263 & 3.00 & 0.92 \\
3 & Com. $\left(a_{*}=3.44\right)$ & -0.052 & 1.90 & 0.70 \\
\hline
\end{tabular}

this trend. However, this test run is not shown in the graphs. Higher discharges were not possible because of the model limitations.

In the presence of a mechanical control barrier (bar screen), regression curves indicate a decay of transport capacity with discharge. Considering the findings of the present study and the physical model study of the Drance, the combination of hydraulic and mechanical control barriers improves the control of sediment retention when a flood threshold discharge is exceeded. Simultaneously, safety against unwanted sediment flushing is increased.

As demonstrated in the present study, the bottom clearance height of the bar screen should be determined independently from the hydraulic barrier. This results in some multiple $f<2$ of the expected sediment size in terms of $D_{84}$. A bar screen that is designed in such a manner, combined with a hydraulic barrier, will also clog in the case whereby the transported grains are smaller than the expected $D_{84}$. As per the Drance study, such a bar screen upstream superposed to a hydraulic barrier clogs even up to $2.6 D_{84}$. The height of the constriction imposed by a hydraulic barrier can be used to adjust the triggering of sediment deposition, as shown in Figs. 13 and 17. The width of the constriction in the overflown hydraulic barrier (cases 1.ii and 3) was slightly larger than the bottom channel width. This aims at avoiding effects of the barrier on the flow up to the occurrence of small frequent floods, to promote longitudinal river continuity.

According to the present study, slot or slit barriers, as mentioned in the introduction, should be used for hydraulic control only (sediment dosing). Inclined lattice barriers, such as the bar screen superposed upstream of a hydraulic barrier applied in this study, are conceivable for sediment sorting and for preventing unwanted sediment flushing during floods. The size of the sorted (retained) sediment is determined as a function of the clearance of the screen, as discussed in the study in terms of the multiplier $f$.

\section{Conclusions}

The present study analyzes the retention of bedload caused by hydraulic control based on discharge and its combination with a mechanical control device. Hydraulic control is prone to the unwanted flushing of formerly deposited sediment. Backfilled, overflown hydraulic barriers may release bedload that can reach even more than $50 \%$ of the bedload transport corresponding to the Smart and Jaeggi (1983) formula.

The retention of bedload by mechanical control is analyzed based on the height of the bottom clearance in terms of some factor of the characteristic grain size. With regard to morphological river continuity, the optimum bottom clearance is the maximum height that still allows for mechanically controlled bedload deposition. This value is found here as $1.75 \cdot D_{84}$ of the sediment supply. If finer bedload is transported, the grains cannot entangle in the mechanical control barrier, which is then ineffective.

The combination of hydraulic and mechanical control barriers enables sediment retention, with a lower sensitivity to the representative grain size and with a lower risk of unwanted sediment flushing. In practice, barriers with flexible opening sizes are sometimes installed to overcome the uncertainties related to each control mechanism. The flexible opening height is linked with legal implications and requires robust hydromechanical equipment, as well as standby duty service. Therefore, the combination of hydraulic and mechanical control barriers, as analyzed in the present study, represents a cost-effective and passively working alternative.

\section{Notation}

\begin{tabular}{|c|c|}
\hline A & flow cross section $\left(\mathrm{m}^{2}\right)$ \\
\hline a & constriction height (m) \\
\hline $\mathrm{a} *$ & relative constriction height (-) \\
\hline $\mathrm{b}$ & constriction width (m) \\
\hline $\mathrm{b} *$ & relative constriction width $(-)$ \\
\hline $\mathrm{D}_{x y}$ & grain diameter of which $x y \%$ of the mixture are finer $(\mathrm{m})$ \\
\hline $\mathrm{F} *$ & grain-related flow velocity (-) \\
\hline f & factor for clearance under mechanical barrier (-) \\
\hline $\mathrm{f}_{\text {opt }}$ & optimum value for $f(-)$ \\
\hline$g$ & gravity acceleration $\left(\mathrm{m} \mathrm{s}^{-2}\right)$ \\
\hline $\mathrm{h}$ & flow depth $(m)$ \\
\hline $\mathrm{h}$ * & relative upstream flow depth $(-)$ \\
\hline $\mathrm{m}$ & channel bank slope $(-)$ \\
\hline $\mathrm{Q}$ & water discharge $\left(\mathrm{m}^{3} \mathrm{~s}^{-1}\right)$ \\
\hline$q *$ & dimensionless unitary discharge $(-)$ \\
\hline $\mathrm{Q}_{b}$ & hydraulic bedload transport capacity $\left(\mathrm{kg} \mathrm{s}^{-1}\right)$ \\
\hline S & channel bottom slope $(-)$ \\
\hline s & ratio of grain and water density (-) \\
\hline $\mathrm{w}$ & channel bottom width (m) \\
\hline $\mathrm{w}_{m}$ & mean flow width $(\mathrm{m})$ \\
\hline$\Phi$ & bedload transport intensity (-) \\
\hline$\nu$ & kinematic viscosity $\left(\mathrm{m}^{2} \mathrm{~s}^{-1}\right)$ \\
\hline$\rho_{f}$ & water density $\left(\mathrm{kg} \mathrm{m}^{-3}\right)$ \\
\hline & grain density $\left(\mathrm{kg} \mathrm{m}^{-3}\right)$ \\
\hline
\end{tabular}

\section{Acknowledgments}

This work is funded by the Swiss Federal Office for the Environment under the research project Sediment and Habitat dynamics. Special thanks goes to Markus Moser (die-wildbach, Austria) and Michael Sturm (Innsbruck University, Unit for Hydraulic Engineering, Austria) for their direct help and for the investigation of case studies related to unwanted sediment flushing. Further thanks goes to Alessandro Reffo (University of Trento), who helped with the experiments on mechanical clogging. The Authors thank the Editor and one anonymous Reviewer for astute and constructive comments that helped to improve the text in important ways.

\section{References}

Ancey, C.C., Bigillon, F. m. c.F. m. c., Frey, P.P., Lanier, J.J., Ducret, R.R., 2002. Saltating motion of a bead in a rapid water stream. Phys. Rev. E 66 (3), 036306.

Armanini, A.A., Larcher, M.M., 2001. Rational criterion for designing opening of slitcheck dam. J. Hydraul. Eng. 127 (2), 94-104.

Bezzola, G.R.G.R., 2008. Unerwartete Prozesse in einem Geschiebesammler [Unexpected processes in a sediment retention basin]. In: Proceedings of INTERPRAEVENT: Sediment / Erosion Control and Avalanche Prevention in the European Alpine Region. International Research Society Interpraevent, Dornbirn, Austria, pp. 271-282.

Bezzola, G.R.G.R., Hegg, C.C., 2007. Ereignisanalyse Hochwasser 2005, Teil 1 - Prozesse, Schäden und erste Einordnung [Event analyses of the 2005 flood, part 1 - Processes, damages and preliminary classification]. Swiss Federal Office for the Environment FOEN / Eidgenössische Forschungsanstalt WSL, Bern / Birmensdorf.

Bezzola, G.R.G.R., Sigg, H.H., Lange, D.D., 2004. Schwemmholzrückhalt in der Schweiz [Driftwood retention in Switzerland]. In: Proceedings of INTERPRAEVENT. International Research Society Interpraevent, Klagenfurt, Austria, pp. 29-40.

Brandt, S.A.S.A., 2000. Classification of geomorphological effects downstream of dams. CATENA 40, 375-401.

Campisano, A.A., Cutore, P.P., Modica, C.C., 2014. Improving the evaluation of slit-check dam trapping efficiency by using a 1D unsteady flow numerical model. J. Hydraul. Eng. 140 (7) (04014024, 1-11).

Canelas, R.B.R.B., Domínguez, J.M.J.M., Crespo, A.C.A.C., Silva, M.M., Ferreira, R.M.L.R.M.L., 2015. Debris flow modelling with high-performance meshless methods. In: Congresso de métodos numéricos em engenharia, pp. 1-14 (Lisbon). 
Chézy, A. d.A. d., 1776. Formula to find the uniform velocity that the water will have in a ditch or in a canal of which the slope is known. In: Collection of Manuscripts in the Library of the Ecole Des Ponts Et Chaussées. (No. 847) of Ms.1915. 61. École des Ponts et Chaussées, Paris, France, pp. 165-269.

Church, M.M., Haschenburger, J.K.J.K., 2017. What is the "active layer"? Water Resour. Res. 53, 5-10.

D’Agostino, V.V., Lenzi, M.A.M.A., 1999. Bedload transport in the instrumented catchment of the rio cordon Part II: analysis of the bedload rate. CATENA 36 (3), 191-204.

Di Stefano, C.C., Ferro, V.V., 2013. Experimental study of the stage-discharge relationship for an upstream inclined grid with longitudinal bars. J. Irrig. Drain. Eng. 139, 691-695.

Di Stefano, C.C., Ferro, V.V., 2014. Closure to "Experimental study of the stage-discharge relationship for an upstream inclined grid with longitudinal bars". J. Irrig. Drain. Eng. 07014028, 1.

die.wildbach, 2016. Hightech am Schnannerbach: Bundesminister Rupprechter Gratuliert Zur Modernen Schutzanlage [Hightech at the Schnannerbach: The Federal Minister Rupprechter Congratulates to the Modern Protection System], Wildbach- und Lawinenverbauung (Abteilung III/5). https://www.bmlfuw.gv.at.

Du Boys, P.P., 1879. Etudes du régime du Rhône et l'action exercée par les eaux sur un lit à fond de graviers indéfiniment affouillable [Studies of the flow of the Rhone and the forces exerted by the waters on an indefinitely erodible gravel bed]. Ann. Ponts Chaussees 5 (18), 141-195.

Einstein, H.A.H.A., 1950. The bed-load function for sediment transport in open channel flows. Techn. Bull. USDA Soil Conserv. Serv. 1026, 71.

Ferguson, R.R., 2007. Flow resistance equations for gravel- and boulder-bed streams. Water Resour. Res. 43, W05427.

Frey, P.P., Tannou, S.S., 2000. Experimental study on bed load control in torrents by open slit dams. In: Joint Conference on Water Resources Engineering and Water Resources Planning and Management, pp. 10 (Minneapolis).

Gabbud, C.C., Lane, S.N.S.N., 2015. Ecosystem impacts of alpine water intakes for hydropower: the challenge of sediment management. Water 3 (1), 41-61.

Ghilardi, T.T., Franca, M.J.M.J., Schleiss, A.J.A.J., 2014. Bed load fluctuations in a steep channel. Water Resour. Res. 50 (8), 6557-6576.

Hager, W.H.W.H., 2010. Wastewater Hydraulics, Theory and Practice, Second edition. Springer-Verlag, Berlin, Heidelberg.

Hübl, J.J., Ganahl, E.E., Bacher, M.M., Chiari, M.M., Holub, M.M., Kaitna, R.R., Prokop, A.A., Dunwoody, G.G., Forster, A.A., Schneiderbauer, S.S., 2006. Dokumentation der wildbachereignisse vom 22./23. August 2005 in tirol, detaillierte aufnahme (unveröffentlicht) [documentation of the torrential floods from 22./23. August 2005 in tyrol, detailed inventory (unpublished)]. IAN Report 109 Band 2 University of Natural Resources and Life Sciences, Vienna, Austria.

Hübl, J.J., Holub, M.M., Suda, J.J., 2005. Structural mitigation measures. In: Bergmeister, K.K., Rickenmann, D.D., Strauss, A.A., Wieshofer, S.S., Curbach, M.M., Proske, D.D. (Eds.), 3Rd Probabilistic Workshop: Technical Systems + Natural Hazards. Schriftenreihe des Departments Nr.7. Universität für Bodenkultur, Department für Bautechnik und Naturgefahren, Vienna, Austria, pp. 115-126.

Hübl, J.J., Holzinger, G.G., Wehrmann, H.H., 2003. Entwicklung Von Grundlagen Zur Dimensionierung Kronenoffener Bauwerke FÜr Die Geschiebebewirtschaftung in WildbÄchen: Klassifikation Von Wildbachsperren [Development of Design Basics for Open-Gap Crested Structures for the Management of Bed Load in Mountain Rivers: Classification Of Torrenital Barriers]. In: WLS Report 50 - Band 2. BMLFUW, pp. 85.

Ikeya, H.H., 1989. Debris flow and its countermeasures in Japan. Bull. Int. Assoc. Eng. Geol. 40 (1), 15-33.

Jordan, F.F., Jaeggi, M.N.M.N., Nigg, U.U., 2003. Modélisation physique d'un piège à graviers, le cas du Baltschiederbach. Wasser Energie Luft 9 (10), 283-290.

Uri, KantonKanton, 2016. Gesamtschau Schutzwasserbau Urner Talboden. In: KOHSTagung, pp. 1-39 (Olten, Switzerland).

Kondolf, G.M.G.M., 1997. Hungry water: Effects of dams and gravel mining on river channels. Environ. Manage. 21, 533-551.

Kramer, H.H., 1932. Modellgeschiebe und Schleppkraft [Modelling bed load and drag force]. 9 Preußische Versuchsanstalt für Wasserbau und Schiffbau.

Lamb, M.P.M.P., Dietrich, W.E.W.E., Venditti, J.G.J.G., 2008. Is the critical Shields stress for incipient sediment motion dependent on channel-bed slope? J. Geophys. Res. 113 (F2), F02008.

Lange, D.D., Bezzola, G.R.G.R., Minor, H.-EH.-E, 2006. Schwemmholz Probleme und Lösungansätze [Driftwood problems and approaches for solutions]. Mitteilung $\mathrm{Nr}$. 188 der Versuchsanstalt für Wasserbau, Hydrologie und Glaziologie an der Eidgenössischen Technischen Hochschule Zürich, Zürich, Switzerland.

Lenzi, M.A.M.A., D’Agostino, V.V., Billi, P.P., 1999. Bedload transport in the instrumented catchment of the Rio Cordon Part I: analysis of bedload records, conditions and threshold of bedload entrainment. Catena 36, 171-190.

Leys, E.E., 1976. Die technischen und wirtschaftlichen Grundlagen in der Wildbachverbauung der großdoligen und der kronenoffenen Bauweise [Technical and economical basics of hydraulic constructions in mountain rivers in terms of large openings and open crested architecture]. Universität für Bodenkultur, Vienna.

Lien, H.-P.H.-P., 2003. Design of slit dams for controlling stony debris flows. Int. J. Sediment Res. 18 (1), 74-87.

Mizuyama, T.T., 2008. Structural countermeasures for debris flow disasters. Int. J. Erosion Control. Eng. 1 (1), 38-43.

Ono, G.-i.G.-i., Mizuyama, T.T., Matsumura, K.K., 2004. Current practices in the design and evaluation of steel sabo facilities in Japan. In: Proceedings of INTERPRAEVENT. International Research Society Interpraevent, Riva, Trient, Italy, pp. 253-264.

Piton, G.G., 2016. Sediment control by check dams and open check dams in Alpine torrents. In: Irstea Grenoble - Equipe ETNA: Erosion Torrentielle, Neige et Avalanches, (Director: Recking, A.).

Piton, G.G., Recking, A.A., 2016a. Design of sediment traps with open check dams. I: hydraulic and deposition processes. J. Hydraul. Eng. 142 (2), 04015045.

Piton, G.G., Recking, A.A., 2016b. Design of sediment traps with open check dams. II: woody debris. J. Hydraul. Eng. 142 (2), 04015046.

Piton, G., Recking, A., 2017. Effects of check dams on bed-load transport and steep-slope stream morphodynamics. Geomorphology 291 (2017), 94-105.

Püntener, P.P., 2006. Hochwasser vom 22./23. August 2005 - schlussbericht zu den bereichen wasserbau und strassen [flood from 22/23. August 2005 - final report on the areas of hydraulic structures and roads]. Amt für Tiefbau des Kantons Uri, Altdorf, $\mathrm{CH}$.

Recking, A.A., 2012. Influence of sediment supply on mountain streams bedload transport. Geomorphology 175-176 (2012), 139-150.

Recking, A.A., 2013. Simple method for calculating reach-averaged bed-load transport. J. Hydraul. Eng. 139, 70-75.

Rickenmann, D.D., 2001. Comparison of bed load transport in torrents and gravel bed streams. Water Resour. Res. 37 (12), 3295-3305.

Rickenmann, D.D., Recking, A.A., 2011. Evaluation of flow resistance in gravel-bed rivers through a large field data set. Water Resour. Res. 47, W07538.

Schleiss, A.J.A.J., Boes, R.R., Doering, M.M., Franca, M.M., Nadyeina, O.O., Pfister, M.M., Robinson, C.C., Scheidegger, C.C., Vetsch, D.D., Weber, C.C., Weitbrecht, V.V., Werth, S.S., 2014. Geschiebe- und habitatsdynamik - forschungsprogramm Wasserbau und Ökologie [The research program Sediment and Habitat Dynamics]. Wasser Energie Luft 106, 117-122.

Schwindt, S., 2017. Hydro-morphological processes through permeable sediment traps. No. 7655. EPF Lausanne, Lausanne, Switzerland (Directors: Schleiss, A.J. and Franca, M.J.).

Schwindt, S.S., De Cesare, G.G., Boillat, J.-L.J.-L., Schleiss, A.J.A.J., 2016. Physical modelling optimization of a filter check dam in Switzerland. In: Koboltschnig, G.G. (Ed.), Proceedings of INTERPRAEVENT: Hazard and Risk Mitigation. 13. International Research Society Interpraevent, Lucerne, Switzerland, pp. 828-836.

Schwindt, S.S., Franca, M.J.M.J., Schleiss, A.J.A.J., 2017. Effects of lateral and vertica constrictions on flow in rough steep channels with bedload. J. Hydraul. Eng. 44. http://dx.doi.org/10.1061/(ASCE)HY.1943-7900.0001389. ([accepted for publication]).

Shields, A.A., 1936. Anwendung der Ähnlichkeitsmechanik und der Turbulenzforschung auf die Geschiebebewegung [Application of the similarity in mechanics and turbulence research on the mobility of bed load], Berlin Edition. 26 Preußische Versuchsanstalt für Wasserbau und Schiffbau.

Shima, J.J., Moriyama, H.H., Kokuryo, H.H., Ishikawa, N.N., Mizuyama, T.T., 2016. Prevention and mitigation of debris flow hazards by using steel open-type Sabo dams. Int. J. Erosion Control. Eng. 9 (3), 135-144.

Simoni, S., Vignoli, G., Mazzorana, B., 2017. Enhancing sediment flux control and natural hazard risk mitigation through a structured conceptual planning approach. Geomorphology 291 (2017), 159-173.

Sindelar, C., Schobesberger, J., Habersack, H., 2017. Effects of weir height and reservoir widening on sediment continuity at run-of-river hydropower plants in gravel bed rivers. Geomorphology 291 (2017), 106-115.

Smart, G.M.G.M., Jaeggi, M.N.R.M.N.R., 1983. Sedimenttransport in steilen Gerinnen [Sediment Transport on Steep Slopes]. Mitteilung Nr. 64 der Versuchsanstalt für Wasserbau, Hydrologie und Glaziologie an der Eidgenössischen Technischen Hochschule Zürich, Zürich.

Sodnik, J.J., Martinčič, M.M., Mikoš, M.M., Kryžanowski, A.A., 2015. Are Torrent CheckDams Potential Debris-Flow Sources? In: Lollino, G.G., Giordan, D.D., Crosta, G.B.G.B., Corominas, J.J., Azzam, R.R., Wasowski, J.J., Sciarra, N.N. (Eds.), Engineering Geology for Society and Territory - Volume 2: Landslide Processes. Springer International Publishing, pp. 485-488.

Suda, J.J., Rudolf-Miklau, F.F., 2008. Schadmechanismen an Wildbachsperren aus Konstruktionsbeton. Wasser Energie Luft 100 (1), 59-68.

Suda, J.J., Strauss, A.A., Rudolf-Miklau, F.F., Hübl, J.J., 2009. Safety assessment of barrier structures. Struct. Infrastruct. Eng. 5 (4), 311-324.

Surian, N.N., Rinaldi, M.M., 2003. Morphological response to river engineering and management in alluvial channels in Italy. Geomorphology 50, 307-326.

Swiss Federal Office for Water and Geology FOWG, 2002. Hochwasser 2000 - les crues 2000 [the floods 2000]. In: Reports of the FOWG, Series Water. 2. FOWG, Bern, pp. 248.

Takahashi, T.T., 2014. Debris Flow: Mechanics, Prediction and Countermeasures, 2nd edition. CRC Press, London, UK.

Uchiogi, T.T., Shima, J.J., Tajima, H.H., Ishikawa, Y.Y., 1996. Design methods for wooddebris entrapment. In: Proceedings of INTERPRAEVENT. 5. International Research Society Interpraevent, Klagenfurt, Austria, pp. 279-288.

Von Karmàn, T.T., 1930. Mechanische Ähnlichkeit und Turbulenz [Mechanical similarity and turbulence]. In: Third International Congress for Applied Mechanics. 1. Stockholm, pp. 79-93.

Wallerstein, N.N., Scott, A.A., Blanc, J.J., 2013. Culvert Design and Operation Guide Supplementary Technical Note on Understanding Blockage Risks. Publication C720 CIRIA, London, pp. 35.

Watanabe, M.M., Mizuyama, T.T., Uehara, S.S., 1980. Review of debris flow countermeasure facilities. J. Japan Erosion Control. Eng. Soc. 115, 40-48.

Wolman, M.G.M.G., Leopold, L.B.L.B., 1957. River Channel Patterns: Braided, Meandering and Straight. Physiographic and Hydraulic Studies of Rivers. 282-B. Geological Survey Professional Paperpp. 1-85.

Wolman, M.G.M.G., Leopold, L.B.L.B., 1957. River Flood Plains some Observations on their Formation. Physiographic and hydraulic studies of rivers. 282-C. Geological Survey Professional Paperpp. 1-107.

Wolman, M.G.M.G., Miller, J.P.J.P., 1960. Magnitude and frequency of forces in geomorphic processes. J. Geol. 68 (1), 54-74.

Yalin, M.S.M.S., 1977. Mechanics of Sediment Transport. 2 Pergamon Press Oxford, 
Oxford and New York.

Zimmermann, A.A., 2010. Flow resistance in steep streams: an experimental study. Water Resour. Res. 46, W09536.

Zollinger, F.F., 1983. Die Vorgänge in einem Geschiebeablagerungsplatz: ihre

Morphologie und ihre Möglichkeiten einer Steuerung [The processes in sediment

traps: their morphology and their possibilities of control]. No. 7419, ETH Zürich,
Zürich, Switzerland. (Directors: Grubinger, H. and Vischer, D.).

Zollinger, F.F., 1984. Die verschiedenen Funktionen von Geschieberückhaltebauwerken [The different functions of debris retention dams]. In: Proceedings of

INTERPRAEVENT. International Research Society Interpraevent, Klagenfurt, Austria, pp. $147-160$. 